\title{
DIGITAL SKILLS DEVELOPMENT FOR FOREIGN LANGUAGES EDUCATION IN UKRAINE
}

\author{
Rusudan Makhachashvili and Ivan Semenist \\ Borys Grinchenko Kyiv University, Ukraine
}

\begin{abstract}
The global pandemic led the higher educational sphere worldwide to the amplified emergency digitalization measures, that sprang from the necessity to take quick comprehensive action to transform educational workflow and both standard and dynamic educational scenarios into digital, blended, and hybrid formats. As a result, there are identified several challenges that higher educational institutions had to face and overcome in a manner that was efficient and expedient: 1) to activate comprehensive complex skillsets, otherwise latent or underutilized in the educational process; 2) to boost ICT competence and digital literacy of all participants of the educational process, relocated to the computer realm. The study objective is informed by the research task to conduct a structured, case-based diagnostics of viral development of digital skills and their application to construe interdisciplinary competencies and professional linguistic competences of students of European and Oriental Languages major programs at Borys Grinchenko Kyiv University (Ukraine), that took place over the span of 2020-2021 due to lockdown measures. The inquiry is founded on the identification of various soft and communicative competency principles and estimated digital literacy components that inform the meta-digital competence in Foreign Languages Education. The empirical study is derived from the comprehensive survey data that disclosed digital literacy components and e-skills implementation in various tiers of professional linguistic and FLE activities. The inquiry determines structural interoperability between different groups of applied e-skills, linguistic competence components and soft skills, necessary for the development of the interdisciplinary professional capacity of Foreign Languages students in Ukraine.
\end{abstract}

\section{KEYWORDS}

Digital Literacy, Viral Digital Skills, Meta-Digital Skills, E-Skills, E-Learning, Foreign Languages Education (FLE)

\section{INTRODUCTION}

Transformative shifts in the knowledge economy of the XXI century, Industry 4.0 development and elaboration of the networked society, emergency digitization due to quarantine measures have imposed pressing revisions onto interdisciplinary and cross-sectorial job market demands 
of Liberal Arts university graduates' skillsets, upon entering the workforce. This, in turn, stipulates reevaluation of the interdisciplinary approaches to comprehensive professional competencies in foreign languages acquisition, education, and application.

The COVID-19 pandemic induced amplified digitalization measures in the higher education sphere, informed by the need to take quick comprehensive action to achieve the overarching result to transform educational scenarios into interdisciplinary digital, remote, and hybrid frameworks.

The consequent functional tasks to meet this challenge in the educational sphere are estimated as 1) adapt the existent educational scenarios to digital, remote and hybrid formats; 2) to upgrade ICT competence and digital literacy of all participants of the educational process; 3) to activate complex interdisciplinary skillsets, otherwise latent or underutilized in the educational process.

These motivations inform the study objective - to diagnose and critically review the empirical case of digital skills development and application to construe interdisciplinary competencies of students of European (English, Spanish, French, Italian, German) and Oriental (Mandarin Chinese, Japanese) Languages major programs at Borys Grinchenko Kyiv University, Ukraine through the span of educational activities in the time-frame of COVID-19 quarantine measures of March 2020 to March 2021.

The inquiry contribution is disclosed through the study design, which includes the following elements:

1) The modeling of interoperability between various competency principles, derivative of twenty-first-century skills (Abbott, 2013), (DosReis, 2015), (Davies \& Fidler, 2011) and projected digital literacy requirements for Foreign Languages Education (FLE) across core digital literacy frameworks (European e-Competence Framework, UNESCO ICT Competence framework for educators and European Commission Digital Competence Framework: DigComp 2020);

2) The survey method application for diagnostic analysis of different digital literacy components and dimensions, as well as digital skills implementation, was used to assess the parameters of efficiency of transforming real-life linguistic education practices into the digital and hybrid format.

3) The identification of the correlation between various groups of applied digital skills and soft skills, instrumental to develop interdisciplinary professional competence of FLE students.

The following grid of groundwork concepts is applied to profile the Foreign Languages Education (FLE) digitization in the COVID-19 timeframe:

- INTERDISCIPLINARITY;

- INTEROPERABILITY;

- $\quad$ DIGITAL LITERACY;

- COMPLEX SKILLS

- VIRAL DIGITAL SKILLS.

The meaning of INTERDISCIPLINARITY is synthesized for the purpose of this study as an agglomeration of two or more fields of knowledge into one scope/goal of study, inquiry, or activity (Callaos \& Marlowe, 2020), (Frodeman, 2017), (Holbrook, 2013), (Jacobs \& Frickel, 2009). 
IADIS International Journal on WWW/Internet

The concept of INTEROPERABILITY is disclosed across different lenses (Interoperability Working Group, 2021), (Slater, 2013) as a characteristic of an object, product or system, that allows its interface to be comprehensible, to work with other objects, products, or systems.

As applied to Foreign Languages Education, the concept of interoperability represents the property of functional, dynamic interconnectivity between the source and target domains of linguistic content, linguistic theory content, related areas of scientific and universal knowledge, and domains of professional and social application.

Interoperability for FLE e-skills is ensured by the communicative nature (Hymes, 1972) of interdisciplinary skills in general. The core cross-sectorial domain that is referential for primary skills (social skills, emotional intellect, collaboration, communication, digital literacy), necessary for educational goals achievement, is estimated to be COMMUNICATION.

DIGITAL LITERACY is defined as the ability to use information and communication technologies to find, evaluate, create, and communicate information, requiring both cognitive and technical skills (DQ report, 2019). Digital literacy and e-skills assessment in the educational context has been subject to academic reevaluation due to the objective conditions of the pandemic global lockdown measures and has been approached through a different lens: regional variation in digital literacy level development in education (Gródek-Szostak et al, 2021); technological challenges for the development of soft skills (Liesa Orús et al, 2020; Troussas et al, 2021); challenges and opportunities of e-learning in higher education (Al-Jardani, 2020; Supriyatno et al, 2020).

The fundamental interdisciplinarity, that COVID-19 digital procedural transformations imposed on the educational process in the area of Foreign languages acquisition, is verified by a unified framework of correspondence between the components of communication (Shannon, 1948) and communicative competence (Hymes, 1972), comprising of a diverse skillset, and various aspects of ICT competence in Foreign Languages Education (European Commission, 2020), (European Commission, 2020), (UNESCO, 2018), utilized in the educational process, elaborated for the purposes of this study (Figure 1):

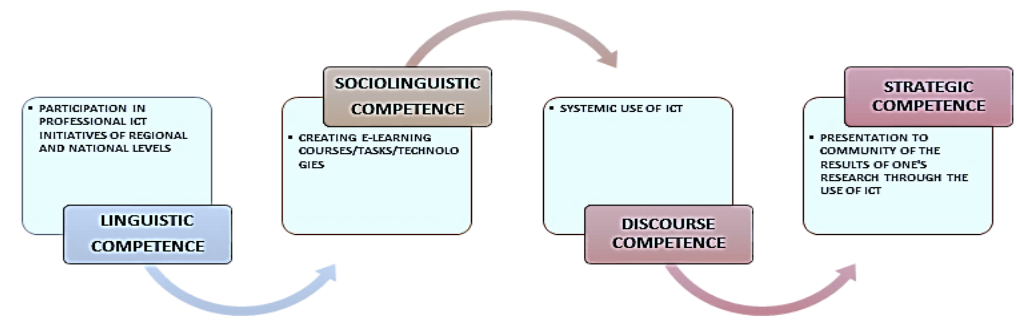

Figure 1. Interdisciplinary Correspondence Between Communicative Competence and ICT Competence in Foreign Languages Education

Interoperability for FLE skills is too ensured by the communicative nature of interdisciplinary skills. The core cross-sectorial domain that is referential for primary skills (social skills, emotional intellect, collaboration, communication, ICT-literacy), necessary for educational goals achievement, is COMMUNICATION.

The digital dimension of communicative interoperability of FLE stems from the structure of Noosphere (Vernadsky, 1991) and content of its components:

- ANTHROPOSPHERE - a set of people as living organisms, their activities and achievements; 
- SOCIOSPHERE - a set of social factors characteristic of this stage of society development and its interaction with nature;

- TECHNOSPHERE - a set of artificial objects created by man, and natural objects, altered as a result of human activity.

A COMPLEX SKILL, subsequently, is defined as a skill requiring to process lots of information and make lots of decisions simultaneously (Wulf \& Shea, 2002).

VIRAL DIGITAL SKILLS for the purpose of this study are defined as rhizomatic capabilities of interoperable manipulation of digital data, tools, and communication formats, acquired institutionally, intuitively or on a peer-to-peer basis.

Given the nature of the increasingly digitalized context of foreign languages education and communicative application ("the Technospheric shift" (Makhachashvili \& Semenist, 2021), it is suggested to consider the different types of information source and information destination (human and machine/computer/program, accordingly) in the structure of the groundwork Communication Model (Shannon, 1948), when communication is approached as the core factor of interoperability of source and target knowledge and application domains in FLE.

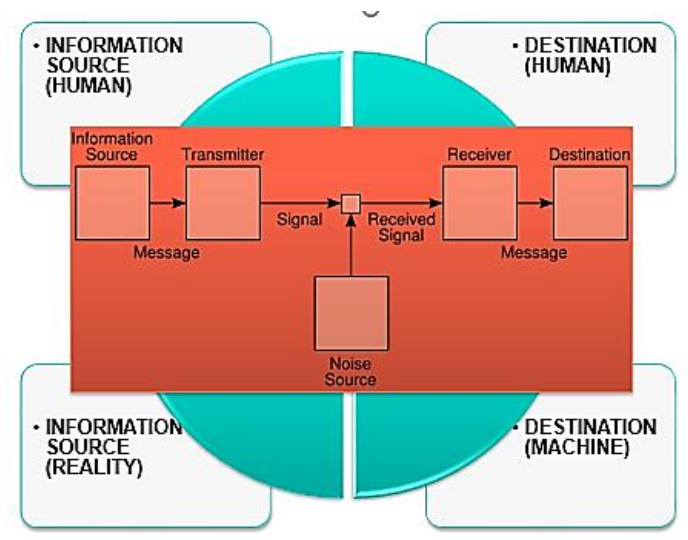

Figure 2. Adaptation of communication model to digitized context of FLE

Subsequently, a model of soft skills paradigms and digital literacy frameworks INTEROPERABILITY in FLE is developed (Figure 3): 


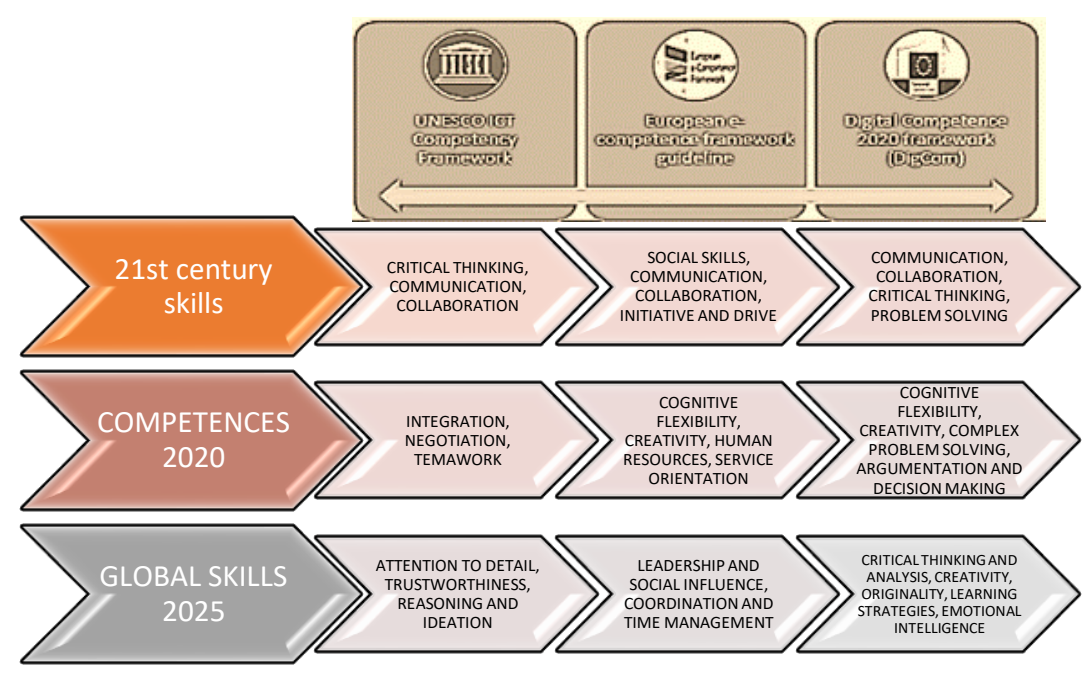

Figure 3. Soft skills paradigms and Digital literacy frameworks interoperability

1) European E-competence Framework Guideline (European Commission, 2020), customized according to European Professional Competence Framework, accommodates the following types of soft skills in terms of digital competence requirements for vocational activity in FLE: service orientation; attention to detail, learning strategies, leadership, and social influence, cognitive creativity and flexibility, coordination and time-management; human resources management;

2) UNESCO ICT Competence framework (UNESCO, 2018), customized for pre-service teachers of foreign languages, accommodates the following types of soft skills in terms of digital competence requirements: collaboration, teamwork, problem-solving, reasoning, and ideation.

3) Digital Competence 2020 framework (European Commission, 2020) for the general public, accommodates the following types of soft skills in terms of digital competence requirements for efficient digital citizenship: Communication and collaboration, creativity and adaptability, learning and innovation, trustworthiness, emotional intelligence, complex problem-solving. Interdisciplinary and transdisciplinary digital skills ensure universal applicability of FLE majors on the job market across various spheres of social activity.

Actual job market demands in various digitized sectors of economy for FLE graduates in the year 2020 (benchmarking conducted across national and international hiring platforms LinkedIn, Indeed.com, Work.ua, Jooble.org, include the positions in the following areas:

- Teacher of language / literature, corporate coach / MOOC tutor / curriculum developer / teacher (negotiation) - EDUCATION

- Translator, proofreader, CAT editor - TRANSLATION, COPYEDITING;

- Researcher (scholar) - writing grants and grant applications, linguist-expert RESEARCH AND DEVELOPMENT, NGO SECTOR; SOCIAL SERVICES; LEGAL SERVICES;

- PR manager, Copywriter, Content manager, SMM - MEDIA COMMUNICATIONS; ADVERTISING, CONTENT-CREATION; 
- Computational linguist (NLP), lexicographer, applied terminologist, digital humanities - IT SECTOR, GAMING INDUSTRY.

Interoperability for FLE digital skills is ensured by the communicative nature (Hymes, 1972) of interdisciplinary skills in general. The core cross-sectorial domain that is referential for primary skills (social skills, emotional intellect, collaboration, communication, digital literacy), necessary for educational goals achievement, is estimated to be COMMUNICATION.

DIGITAL META-COMPETENCE in its turn is defined as the ability to apply information and communication technologies, requiring both advanced cognitive and technical skills (ALA, 2020), (Heim 1993), (TDD, 2020) across the board of professional spheres of human activity. Digital literacy within the structure of digital competence, thus, acquires the transcendent status of meta-literacy.

Therefore, the fundamental meta-learning status, that COVID-19 digital procedural transformations imposed on the educational process in the area of Foreign languages acquisition, is verified by a unified model of correspondence between the components of professional competence in FLE (Holbrook 2013), comprising of a diverse communicative skillset, and digital meta-competence (DGGSR 2019), (Eduvantures, 2020), (Hymes 1972), (Makhachashvili, Semenist 2021), instrumental to the variable communicative dimensions activation, elaborated for the purposes of this study (Figure 4):

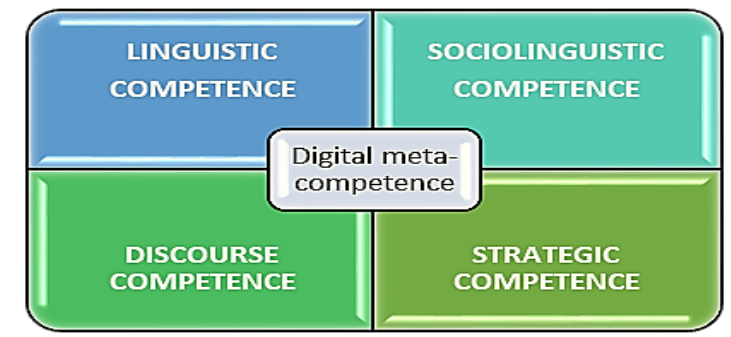

Figure 4. Model of Correspondence Between Communicative Dimensions and Digital Meta-Competence in FLE

Therefore, a DIGITAL META-SKILL in FLE, consequently, for the purpose of the study is defined as a transcendent capability of processing and management of digital data, digital tools, interdisciplinary knowledge domains and communication formats, utilized across all types of foreign language mediated professional, educational and individual interaction. 


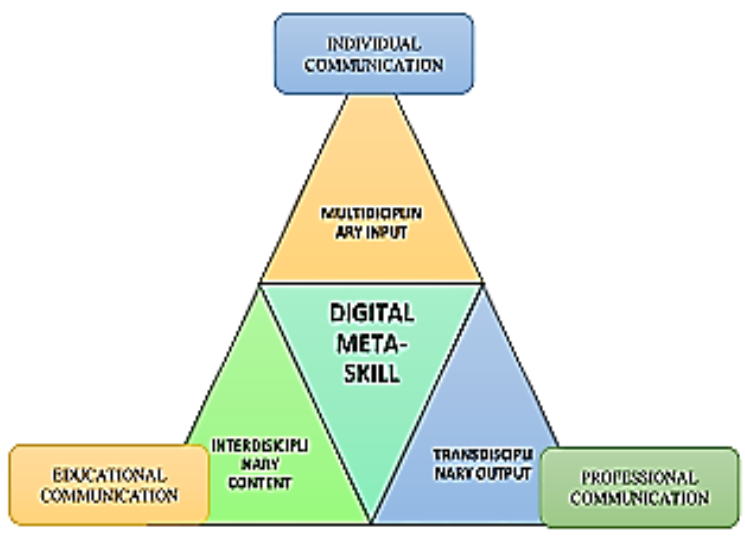

Figure 5. Model for Digital meta-skills in FLE

The study suggests and empirically verifies a model (Figure 5) of digital skills meta-status that transcends the correlation across the interdisciplinary domains of FLE and foreign language professional application in different spheres.

\section{E-SKILLS AND DIGITAL LITERACY FOR FOREIGN LANGUAGES EDUCATION: SURVEY RESULTS}

\subsection{Method Overview}

The study employs the combination of mixed methods (Almalki 2016) - a proportional arrangement of quantitative and qualitative inquiry to assess in-depth aspects of subjective and individual quality estimation of digital distance and hybrid learning. The comprehensive study design methodology included the following consecutive steps:

1) The qualitative profiling of various competency principles, derivative of twenty-first-century skills (Abbott, 2013), (DosReis, 2015), (Davies \& Fidler, 2011), (Makhachashvili \& Semenist 2021), and digital literacy requirements for Foreign Languages Education (FLE) across digital literacy frameworks (European e-Competence Framework, UNESCO ICT Competence framework for educators and European Commission Digital Competence Framework: DigComp 2020);

2) The online survey method - based on D. Dillman's concept of mixed media and mixed-mode surveys (Dillman 2014) - applied to conduct an in-depth assessment of different digital literacy components and dimensions, as well as digital skills implementation, used to assess the parameters of efficiency of transforming real-life linguistic education practices into the digital and hybrid format in Oriental and European Languages university level programs at Borys Grinchenko Kyiv University, Kyiv, Ukraine;

3) The evaluation of interoperability between various groups of applied digital skills and soft skills, instrumental to develop interdisciplinary professional competence of FLE students. 
Based on the digital literacy profile of FLE (e-skills frameworks, customized for Foreign Languages Education) an online survey was devised to assess in-depth subjective experiences of e-learning and hybrid learning in the COVID-19 timeframe (March 2020 - March 2021) for students of Oriental languages (Mandarin Chinese and Japanese) and European Languages (French, Italian, Spanish, English, German) major programs.

The survey structure comprised of 16 complex diagnostic questions (multiple-choice, criteria comparison, and Likert scale score types), divided into the following categories: 1) questions on the overall assessment of digital literacy level in the framework of COVID-19 lockdown and quarantine measures for university programs of Oriental and European languages; 2) questions on diagnostics of future specialists in FLE according to the established frameworks of digital competencies and e-skills in the professional field; 3) questions on diagnostics of interoperability of linguistic/communicative/soft professional and digital skills for university programs of European and Oriental languages.

\subsection{Data Gathering}

A sizable sample of 235 respondents total across 7 Foreign Languages Programs - Oriental (Mandarin Chinese, Japanese) and European (English, French, Spanish, Italian, German) languages at Borys Grinchenko Kyiv University took part in the survey. The following groups of stakeholders of the digital distant education in the timespan of COVID-19 pandemic measures were respondents of the survey overall on all three tiers of educational levels according to the legislature of Ukraine (Law OHE 2019): undergraduate, graduate, and post-graduate: 1) students of Bachelor's programs for Oriental (Mandarin Chinese, Japanese) and European (French, Italian, Spanish, English, German) languages (1st, 2nd, 3rd and 4th years of study) - 93.6\%; 2) students of Master's programs for Oriental (Mandarin Chinese, Japanese) and European (English, French, Spanish, Italian, German) languages (1st and 2nd years of study) - 4.3\%; students of Post-graduate programs for Oriental (Mandarin Chinese, Japanese) and European (French, Italian, Spanish, English, German) languages (1st, 2nd, 3rd and 4th years of study) $2.1 \%$.

For the purposes of this paper, the survey results were scaled to accommodate the sample of students of Oriental (Mandarin Chinese, Japanese) and European (French, Italian, Spanish, English, German) languages programs of Borys Grinchenko Kyiv University of Ukraine (Kyiv being the capital city). This limitation was adopted to assess the case of best practices of educational digitization to estimate the parameters and challenges of the individual experiences and digital skills development in the framework of COVID-19 lockdown, comprehensively implemented at Borys Grinchenko Kyiv university since the first days of the global lockdown in March of 2020 and thereon, as a parcel of the university overall digital campus and digital literacy implementation policy.

\subsection{Survey Results and Discussion}

Group 1 of survey questions - overall assessment of digital literacy level in the framework of COVID-19 lockdown and quarantine measures for university programs of Oriental and European languages - yielded the following representative results across the board. 
IADIS International Journal on WWW/Internet

Estimation of overall digital literacy level in the framework of COVID-19 lockdown for university programs of Oriental and European languages was conducted according to the 5-Point Likert Scale (a response scale in which responders specify their level of engagement with a statement or a parameter in five points: (1) Strongly disagree; (2) Disagree; (3) Neither agree nor disagree; (4) Agree; (5) Strongly agree (Handbook 2010). The extremum points for evaluation were 1 (maximum negative overall mastery of the given digital literacy level) and 5 (maximum positive overall mastery of the given digital literacy level).

The qualitative dimensions provided for evaluation were: Elementary digital literacy; Medium digital literacy; Advanced digital literacy; No defined digital literacy level.

The quantitative assessment of individual digital level yielded a range of scalable results (Figure 6):

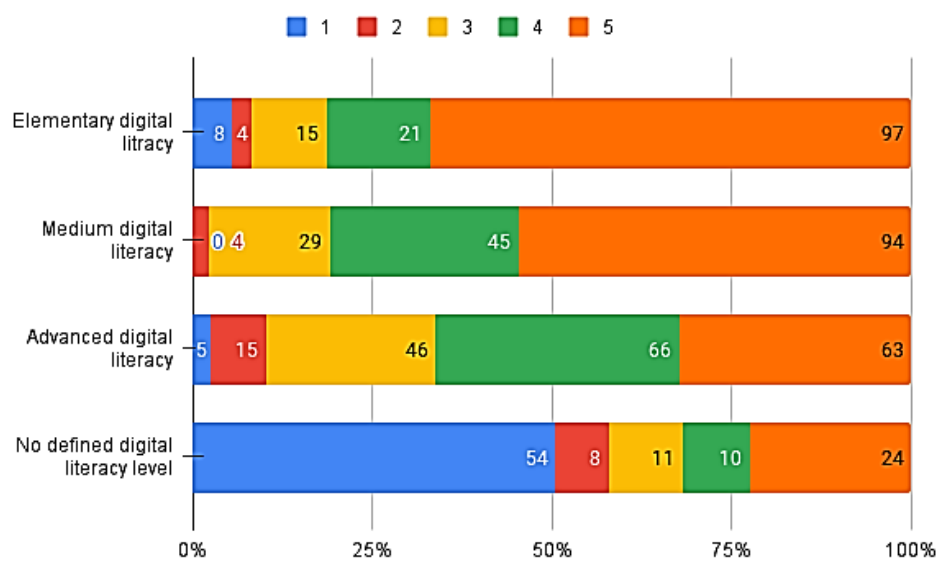

Figure 6. Assessment of Individual Digital Level

Stakeholders of European and Oriental languages programs evaluated their individual digital literacy levels in the COVID-19 timeframe as predominantly advanced (83\% of respondents) and medium $(73.2 \%)$. However, the elementary and medium digital literacy levels were assessed with the highest standard deviation of score range $(\mathrm{SD}=34)$. These levels of digital literacy mastery were assessed as predominantly 5 (maximum positive overall mastery of the given digital literacy level): Elementary level - 41.3\%; Medium level $-40 \%$ of respondents.

Comparative evaluation of individual digital literacy level for university programs of Oriental and European languages during and prior to the framework of COVID-19 lockdown (Figure 4) allowed to estimate the dynamics of digital literacy from the timespan before the global pandemic measures and through the emergency online education of 2020-2021: 


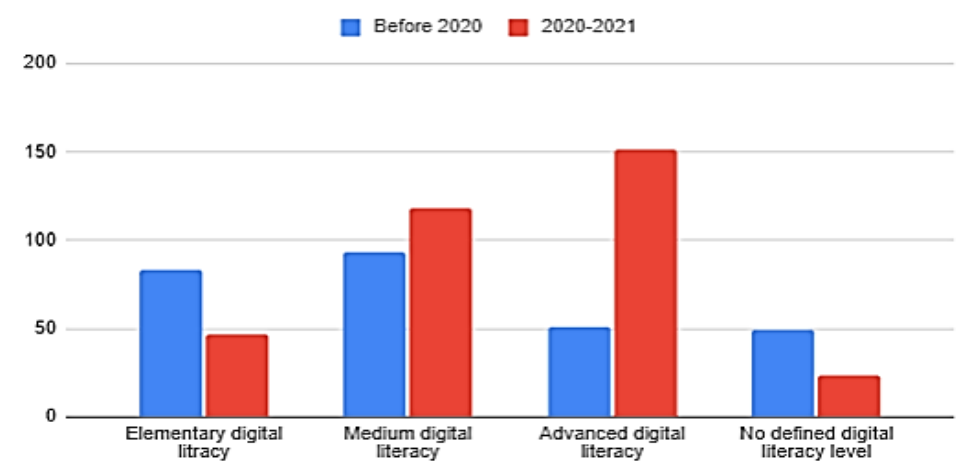

Figure 4. Comparative evaluation of individual digital literacy level

Digital literacy level in the timeframe before 2020 is estimated by the stakeholders of Oriental and European languages university programs as predominantly Elementary (35.3\%) to Medium (39.6\%). Digital literacy level in the timeframe of Covid-19 quarantine measures of 2020-2021 is estimated by the stakeholders of Oriental and European languages university programs was estimated as predominantly Medium (50.2\%) to Advanced (64.3\%). The estimated positive dynamics of the digital literacy mastery by Foreign Languages students comprise $+10 \%$ for the Medium level and $+42 \%$ for the Advanced level. There's a notable drop in the score for the 'No defined digital literacy level' dimension of assessment between the compared timespans of pre-pandemic and during the pandemic emergency online learning measures $(20.8 \%$ decreased to $10.2 \%$ accordingly).

Group 2 of survey questions - diagnostics of future specialists in FLE according to the established frameworks of digital competencies and e-skills in the professional field- yielded the following representative results across the board.

Group 2.1 of questions - Diagnostics of future specialists in FLE according to European e-Competence Framework and estimation of digital skills of FLE for professional application - allowed to evaluate of the professional e-competence dimensions for FLE students among the following: A. PLAN, B. BUILD, C. RUN, D. ENABLE, and E. MANAGE professional processes with the help of digital tools and services.

Within the given dimensions the following top-scoring professional goals of FLE students were estimated (Figure 5): 1) Planning of professional processes (in the field of or with the help of foreign languages) (A) $-60.8 \%$ of respondents; 2 ) Monitoring of professional activity (in the field of or with the help of foreign languages) (C) $-49.8 \%$ of respondents; 3) Provision (facilitation) of professional activity (in the field of or with the help of foreign languages) (D) $-46.3 \%$ of respondents. According to the prioritized professional goals, the following dominant professional e-competence dimensions for FLE students are identified (Table 1): 1) to PLAN; 2) to RUN; 3) to ENABLE professional processes in Foreign Languages application (communication and education). 


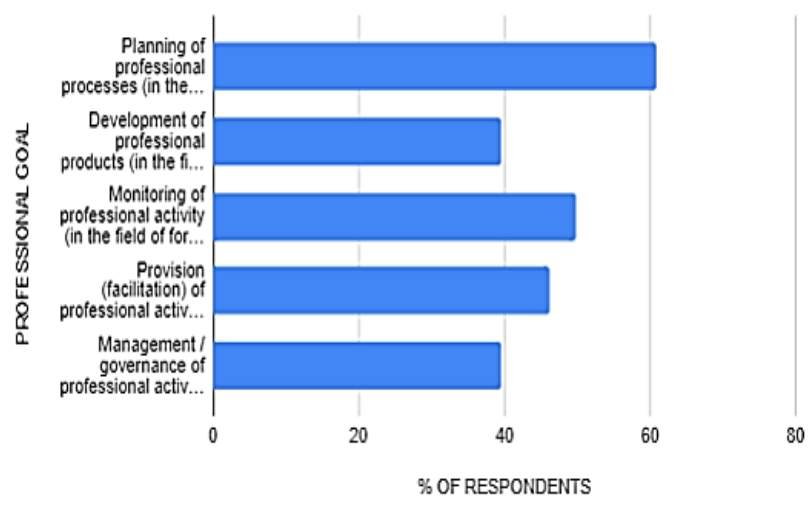

Figure 5. FLE to implement digital tools for professional goals

Table 1. FLE to implement digital tools for professional goals

\begin{tabular}{lll}
\hline PROFESSIONAL GOAL & $\%$ OF RESPONDENTS & $\begin{array}{l}\text { DIGITAL COMPETENCE } \\
\text { DIMENSION } \\
\text { A. PLAN }\end{array}$ \\
$\begin{array}{l}\text { Planning of professional } \\
\text { processes (in the field of } \\
\text { foreign languages) (A) } \\
\begin{array}{l}\text { Development of professional } \\
\text { products (in the field of } \\
\text { foreign languages) (B) }\end{array}\end{array}$ & 60,8 & B. BUILD \\
$\begin{array}{l}\text { Monitoring of professional } \\
\text { activity (in the field of foreign } \\
\text { languages) (C) }\end{array}$ & 39,6 & C. RUN \\
$\begin{array}{l}\text { Provision (facilitation) of } \\
\text { professional activity (in the } \\
\text { field of foreign languages) } \\
\text { (D) }\end{array}$ & 49,8 & D. ENABLE \\
$\begin{array}{l}\text { Management/governance of } \\
\text { professional activities (in the } \\
\text { field of foreign languages) (E) }\end{array}$ & 46,3 & \\
\hline
\end{tabular}

Therefore, the priority types of dominant digital skills for professional application of FLE students according to the European e-competence framework are estimated as 1) ICT user skills $-74.25 \%$ of respondents; 2) ICT practitioner skills $-72.75 / \%$ of respondents.

According to the Likert Scale, assessment ICT user skills get a top ranking of 4 (46\% of respondents) and ICT practitioner skills get a top ranking of 5 (37\% of respondents).

The following specific digital skills for Foreign Languages professionals correspond to the prioritized types:

1) ICT PRACTITIONER SKILLS: Skills for language and communication research; Skills for strategic planning of communication; Skills for communicative management; Skills for consulting;

2) ICT USER SKILLS: Skills for the effective application of ICT systems and devices; Skills to apply ICT systems as tools in support of one's work; User skills for common software tools and specialized tools supporting business functions within professional area of foreign languages use.

Highest assessed separate digital skills for Foreign Languages professionals (score 5 - most relevant for Foreign Languages professionals) are determined to be: 1) 
The general underperformance of E-business skills type in the assessment of stakeholders ( $41 \%$ of respondents) testifies to the lack of entrepreneurial orientation of Foreign Languages Education in Ukraine in general and overall public/state service orientation of the Foreign Languages/Philological jobs market in general.

The comparative assessment of general types of digital skills for professional application of FLE students in the pre- Covid-19 (before 2020) and Covid-19 proper quarantine measures (2020-2021) timeframe yielded the range of quantitative and qualitative results. Three formats of Foreign languages learning were compared:

1) Traditional learning (pre-2020);

2) Online learning (2020-2021);

3) Hybrid learning (2020-2021).

Online learning and hybrid learning were the two interchangeable formats, adopted by Borys Grinchenko Kyiv University through the pandemic emergency measures, depending on the week-to-week quarantine assessment.

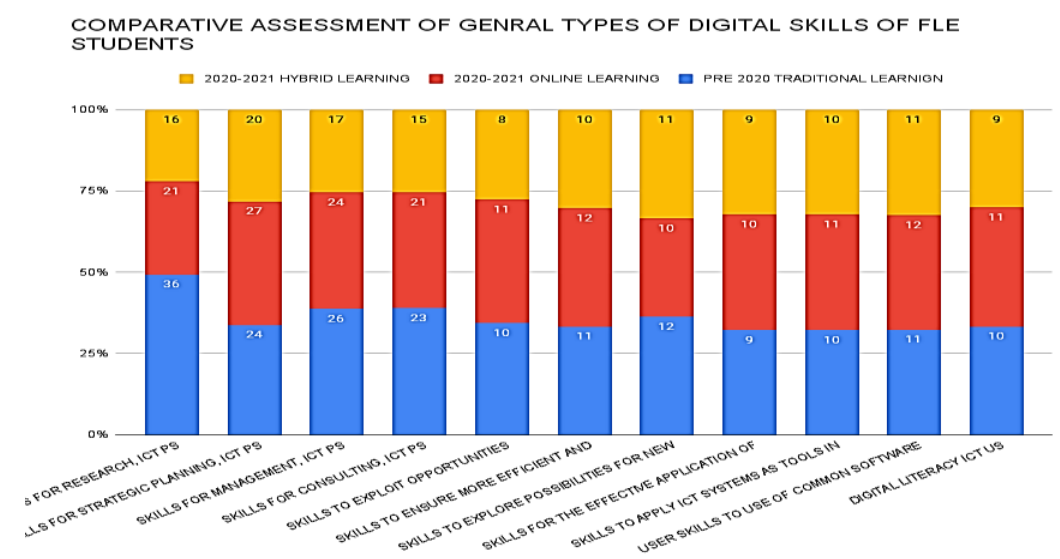

Figure 6. Comparative assessment of digital skills for professional application of FLE students

The comparative assessment of general types of digital skills across different paradigms of learning allowed to identify the following top-scoring digital skills, estimated as significant for Foreign languages education and professional application in the pre-pandemic timeframe (Figure 6): 1) Skills for language and communication research (49.3\% of respondents); 2) skills for communicative management (39\% of respondents); 3) Skills for consulting (38.2\% of respondents).

The top-scoring digital skills, estimated as enhanced for Foreign languages education and professional application in the pandemic timeframe (2020-2021) through the format of online learning are as follows: 1) skills for strategic planning (38\% of respondents); 2) skills to exploit opportunities, provided by ICT (37.4\% of respondents); 3 ) skills to ensure more efficient and effective performance of different types of organizations (36.4 of respondents); 4) Skills for communicative management (36\% of respondents).

As can be concluded, the dynamics of digital skills enhancement and real-life application by FLE professionals in the pandemic paradigm provided for the prominence of E-business skills, otherwise latent or underdeveloped in the Foreign Languages education context and professional field. 
Group 2.2 of questions - Diagnostics of digital skills of FLE for pre-service and in-service teachers according to UNESCO ICT Competence Framework for Educators - allowed to identify 1) professional activity goals of FLE pre-service teachers for digital skills application and 2) student-oriented goals of FLE pre-service teachers for digital skills application.

Qualitatively, professional activity goals of FLE pre-service teachers for digital skills application were identified as follows (Figure 7): to develop curricula using digital tools; to develop learning materials using digital tools; to understand the role of digital technologies in language education; to develop strategies and tactics for learning foreign languages at different levels using digital tools; to develop assessment tools and models using digital tools; to choose a pedagogical strategy and implement it with the help of digital tools; to organize and administer the learning process using digital tools; to improve one's teaching skills with digital tools.

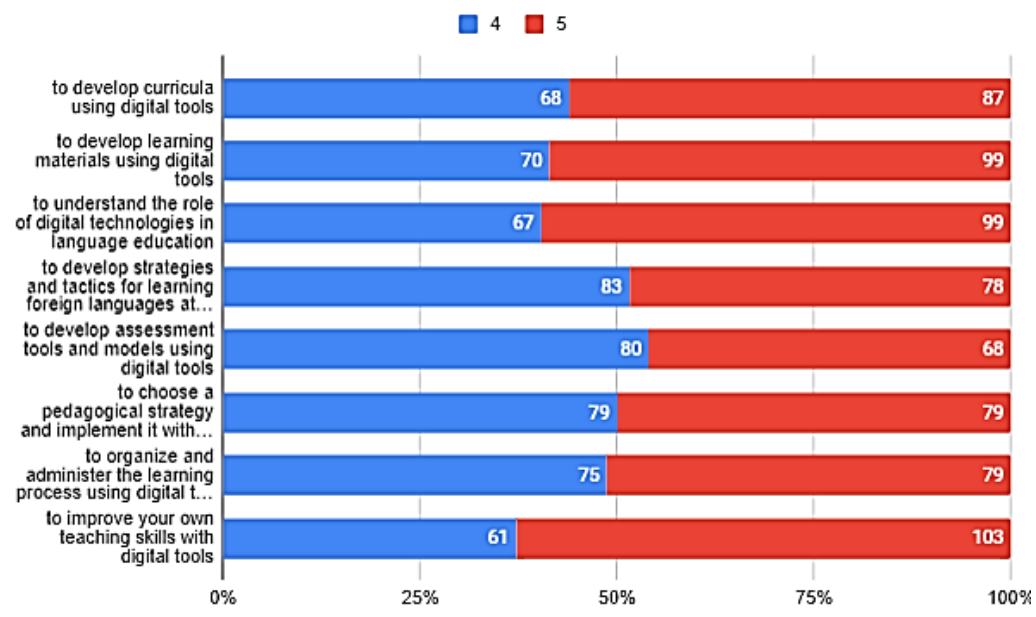

Figure 7. Professional activity goals of FLE pre-service teachers for digital skills

Quantitatively, the priority (scoring 5-4 on the evaluation scale) professional activity goals of FLE pre-service teachers for digital skills application are estimated by the stakeholders as:

1) to improve one's teaching skills with digital tools ( $62.8 \%$ of respondents);

2) to develop learning materials using digital tools (58.6\% of respondents);

3 ) to understand the role of digital technologies in language education $(58.6 \%$ of respondents);

4) to develop curricula using digital tools (51.6\% of respondents).

Qualitatively student-oriented goals of FLE pre-service teachers for digital skills application were identified as follows (Figure 8): to teach digital literacy in general; to teach to process language data using digital tools; to teach to implement different types of speech activities via digital tools (oral, written, listening, dialogue, monologue); to identify individual learning needs and gaps in foreign language skills using digital tools; to identify group learning needs and gaps in foreign language skills using digital tools; to teach to work in a team / organize collaboration; to teach to organize communication of different types with the help of digital tools; to teach to think critically using digital tools; to teach to solve problems with digital tools; to help learn independently via digital tools; to help become effective participants in civil society through digital tools. 


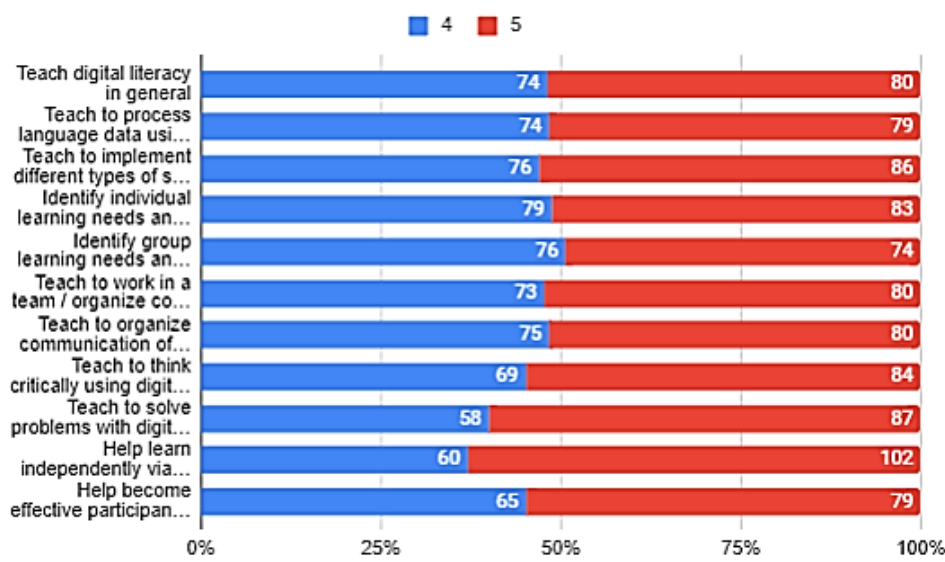

Figure 8. Student-oriented goals of FLE pre-service teachers for digital skills application

Quantitatively, priority (scoring 5-4 on the evaluation scale) student-oriented goals of FLE pre-service teachers for digital skills application are estimated as: 1) to help learn independently via digital tools (63\% of respondents); 2 ) to help to become effective participants in civil society through digital tools $(60.3 \%$ of respondents); 3 ) to teach to solve problems with digital tools (60\% of respondents); 4) to teach to think critically using digital tools (55\% of respondents); 5 ) to teach to implement different types of speech activities (oral, written, listening, dialogue, monologue) $-53.1 \%$ of respondents; 6 ) to teach to work in a team / organize collaboration (52.3\% of respondents);

It bears pointing out that the dominant students-oriented goals for digital skills application correspond to the generic soft skills, identified across various frameworks: 1) Learning and innovation; 2) human resources management, social intellect; 3) problem solving and critical thinking; collaboration and communication.

The student-oriented goals for digital skills application, interoperable with the professional language acquisition and communication activity are ranked relatively low by the stakeholders: to teach to implement different types of speech activities via digital tools $-53.1 \%$ of respondents; to teach to process language data using digital tools $-52 \%$ of respondents; to identify individual learning needs and gaps in foreign language skills using digital tools $-51.2 \%$ of respondents.

Group 2.3 of questions - Diagnostics of future specialists in FLE according to European Commission DigComp 2020 Framework - ensured assessment of digital skills of FLE for digital citizenship.

Qualitatively, digital competence dimensions for digital citizenship, enhanced by FLE (foreign languages education) are identified as (Figure 10): 1) Information and data literacy; 2) Communication and collaboration; 3) Digital content creation; 4) Safety; 5) Problem-solving. 
IADIS International Journal on WWW/Internet

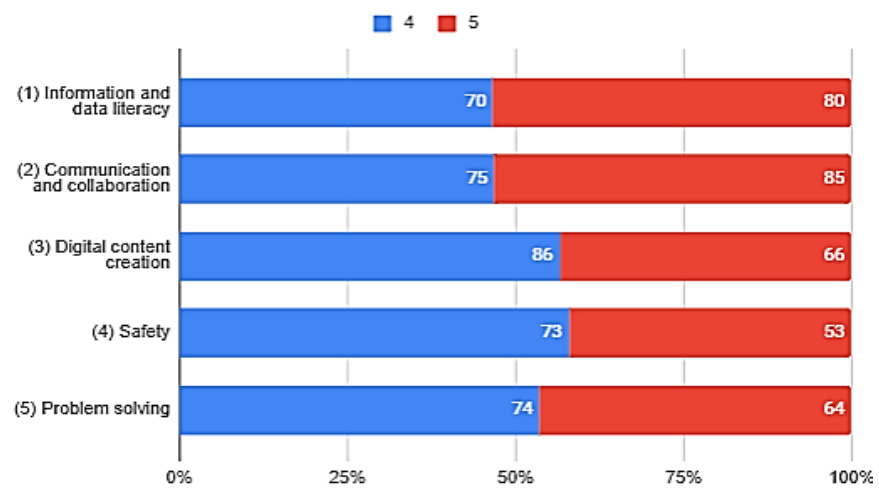

Figure 10. Digital competence dimensions for digital citizenship, enhanced by FLE

Quantitatively, the dominant (scoring 5-4 on the evaluation scale) digital competence dimensions for digital citizenship, enhanced by FLE are estimated by the stakeholders as (Figure 11): 1) Information and data literacy (53.3\% of respondents); 2) Communication and collaboration (53.1\% of respondents); 3) Problem solving (46.4\% of respondents).

Within the identified priority digital competence dimensions for digital citizenship, the dominant (scoring 5-4 on the evaluation scale) digital activities mastery in FLE, enhanced through COVID-19 timeframe was estimated as follows (Figure 11):

1) to keep up-to-date with the digital evolution ( $62 \%$ of respondents);

2 ) to articulate information needs, to locate and retrieve digital data, information and content (60\% of respondents);

3 ) to interact, communicate and collaborate through digital technologies while being aware of cultural and generational diversity (58.3\% of respondents);

4 ) to create and edit digital content (56.5\% of respondents); to judge the relevance of the source and its content ( $56 \%$ of respondents);

$5)$ to store, manage, and organize digital data, information, and content $(55 \%$ of respondents).

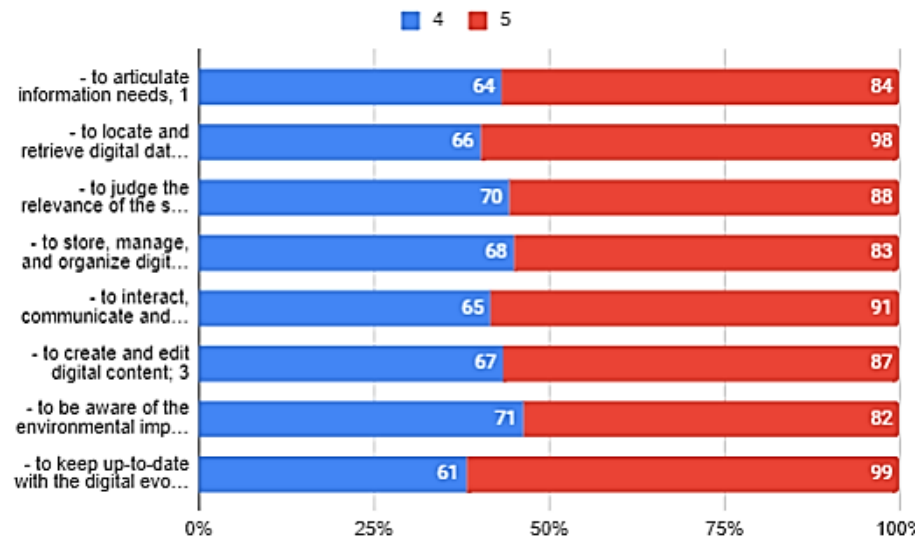

Figure 11. Digital activities mastery in FLE 
The majority of digital activities in FLE, estimated as activated through COVID-19 timeframe refer to dimension (1) Information and data literacy of the digital competence (to articulate information needs; to locate and retrieve digital data; information and content; to judge the relevance of the source and its content; to store, manage, and organize digital data, information and content. However, the highest-scoring digital activities represent underlying interoperability of FLE through the COVID-19 paradigm with such dimensions of digital competence as (5) Problem solving (to keep up-to-date with the digital evolution) and (2) Communication and collaboration (to interact, communicate and collaborate through digital technologies while being aware of cultural and generational diversity).

Group 3 of survey questions - Diagnostics of interoperability of linguistic/communicative/soft professional and digital skills for university programs of FLE yielded the following comprehensive results.

Digital communication elements, instrumental for professional linguistic competence formation were evaluated (Figure 12). Qualitatively, the Linguistic competence components were synthesized as: Linguistic (Semiotic) Competence; Sociolinguistic Competence; Discoursive Competence; Strategic Competence. Across different frameworks, digital communication components in FLE were synthesized as: Participation in group ICT initiatives; Creation of e-learning courses/tasks; Systemic use of ICT; Presentation to the community of the results of one's activity via ICT.

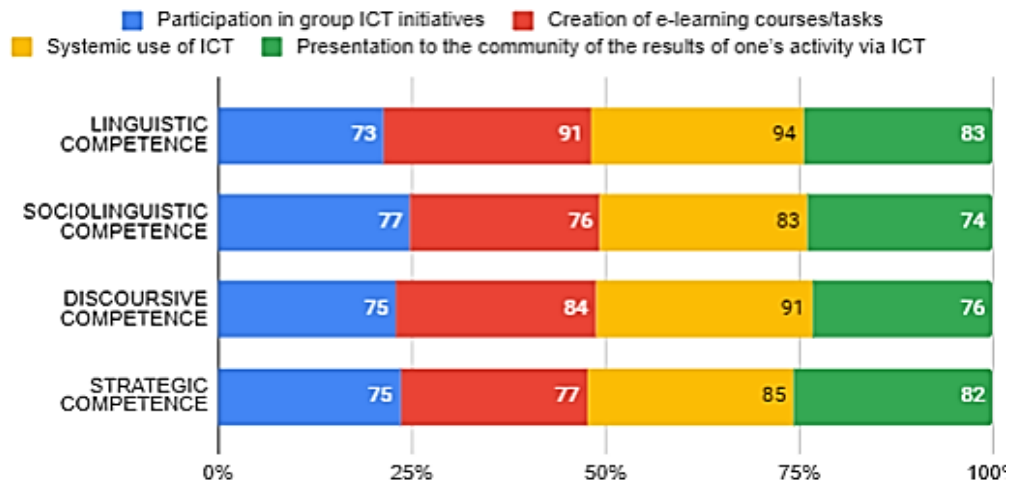

Figure 12. Digital communication elements, instrumental for professional linguistic competence formation

Dominant combinations of digital communication elements, instrumental for professional linguistic competence formation are estimated as follows: 1) linguistic (semiotic) competence is enhanced by such elements of digital communication as the creation of e-learning content (26.7\%), systemic use of ICT $(27.6 \%)$; 2) sociolinguistic competence is enhanced by such elements of digital communication as participation in group ICT initiatives (25\%), systemic use of ICT (27\%); 3) discoursive competence is enhanced by such elements of digital communication as systemic use of ICT $(28 \%)$, creation of e-learning content $(26 \%)$; 4) strategic competence is enhanced by such elements of digital communication as systemic use of ICT (27\%), presentation to the community of the results of one's activity via ICT $(26 \%)$.

Professional linguistic competence elements, instrumental for digital communication (Figure 13) were evaluated by the Foreign Languages stakeholders. 
IADIS International Journal on WWW/Internet

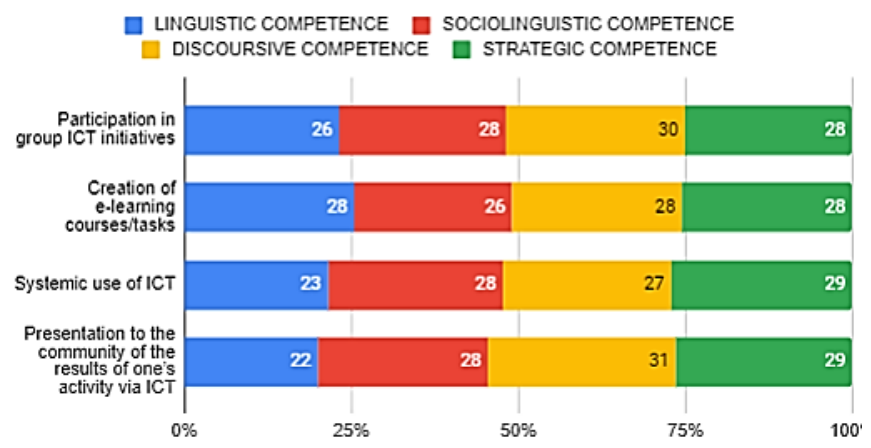

Figure 13. Professional linguistic competence elements, instrumental for digital communication

Dominant linguistic competence elements, instrumental for digital communication (Figure 10) were evaluated as follows: 1) discoursive competence is estimated as dominant for participation in group ICT initiatives $(27 \%)$; 2) linguistic (semiotic) competence and strategic competence are estimated as dominant for creation of e-learning content (25.5\%); 3 ) sociolinguistic competence $(26.2 \%)$ and strategic competence $(27.1 \%)$ are estimated as dominant for systemic use of ICT; 4) discoursive competence is estimated as dominant for presentation to the community of the results of one's activity via ICT (28.2\%).

Digital competence dimensions effective for the implementation of foreign language acquisition activities (Figure 14) were assessed by the Foreign Languages programs stakeholders. The following set of foreign language acquisition activities was identified and evaluated: Oral monologue; Oral dialogue; Small group communication; Public speech; Written literary communication; Written business communication; Written private communication; Listening; Active vocabulary; Passive vocabulary; Grammar skills; Phonetic skills; Rhetorical skills; Stylistic skills.

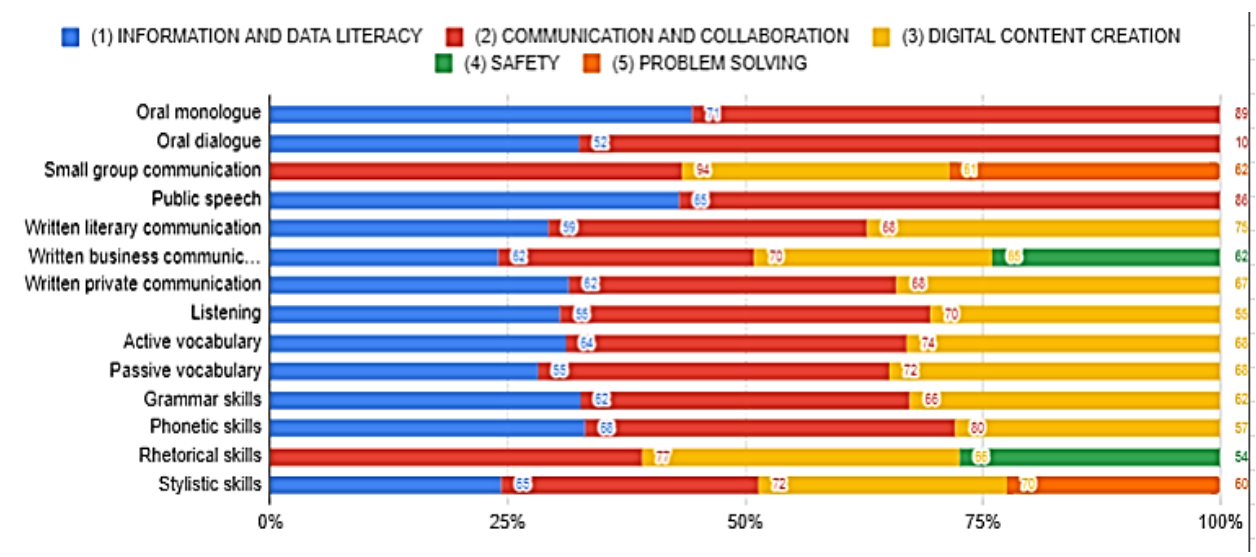

Figure 14. Digital competence dimensions for foreign language acquisition activities

Key digital competencies, effective for the implementation of foreign language acquisition activities, were quantified as follows: 1) for Oral speech activities the dominant digital competencies are Information and data literacy (43.1\%), Communication and collaboration 
(61\%); 2) for Written speech activities the dominant digital competences are Communication and collaboration (33.7\%), Digital content creation (32.6\%), Safety (24\%); 3) For Audial activities the dominant digital competences are Information and data literacy (39\%), Communication and collaboration (30.6\%), Digital content creation (30.6\%); 4) For Vocabulary acquisition activities the dominant digital competences are Communication and collaboration $(36 \%)$ and Digital content creation $(34.1 \%) ; 5)$ for Stylistic acquisition activities the dominant digital competences are Communication and collaboration (39.1\%), Digital content creation $(32.5 \%)$, Problem-solving $(27.4 \%)$.

\section{CONCLUSION}

The global pandemic emergency e-learning measures and underlying shift in the digital economy informed the comprehensive modeling of interoperability between various competency principles, derivative of the soft marketable skills, and projected digital literacy requirements for foreign languages education across core digital literacy frameworks. The comprehensive diagnostics of the dimensions of digital competence for foreign languages education across actual frameworks has disclosed the interoperability of soft skills and digital communication skills across contrasting timeframes and stages of foreign languages acquisition by students of European and Oriental Languages programs and early career training.

Various levels of digital literacy have been identified in the inquiry in the sampled university of Ukraine. Across the board, implementation of Foreign Languages Education in the emergency online learning paradigm requires of participants of educational process medium to advanced digital literacy.

Digital domain, digital communication, and digital literacy are assessed as interoperable parameters across different e-competence frameworks, that inform underlying interdisciplinarity of foreign languages education in the timespan of the Covid-19 emergency e-learning measures.

Evaluation of digital skills of FLE for professional application allowed to determine the priority dimensions of professional e-competence as to plan, to run, and to enable professional processes in foreign languages application. The types of dominant digital skills for professional application of FLE are identified as ICT user skills and ICT practitioner skills. The demands of the digital and knowledge economy job market are not met by the liberal arts curriculum design, as the $e$-business skills are evaluated scoring lowest in priority by FLE stakeholders.

Assessment of digital skills of FLE for pre-service and in-service teachers indicated priority professional activity goals and student-oriented goals for digital skills application to be interoperable with such soft skills types as learning and innovation, cognitive flexibility, and service orientation.

Evaluation of digital skills of FLE for digital citizenship allowed to determine the priority e-competence dimensions, activated by formal linguistic training or consistent foreign languages use: Information and data literacy; Communication and collaboration; Problem-solving.

The dominant interoperable skills, acquired through FLE, are: communication, emotional intellect, creativity, problem-solving, and innovation. Digital literacy features as a prominent interoperable skill, facilitating the application of other types of soft skills of a communicative nature. 
IADIS International Journal on WWW/Internet

The study findings helped to detect challenges for actual and underdeveloped skills (hard, technical, and soft), that stakeholders of the European and Oriental languages education encountered through digital format adaptation in the COVID-19 timeframe, such as: 1) Digital literacy challenges: Lack of proficiency in the use of LMS tools for specific purposes; Lack of proficiency in use of specific communicative interface options; Lack of proficiency in use of Google Suite tools for collaboration; Lack of proficiency in the use of mobile versions of e-learning platforms, tools and services, used in FLE workflow; 2) Digital divide in the accessibility of computer and online technologies, necessary for all stages of Foreign Languages Education: Internet bandwidth and stability of connection; Update of PC hardware and software; Access to back-up smart devices to carry out the FLE; 3) Soft skills challenges: Learning and innovation (professional activity outside of the comfort zone); Cognitive flexibility; Entrepreneurial outlook; Time-management; Collaboration and networking via digital media; Emotional intelligence and awareness; Critical thinking and decision making.

The comprehensive study results inform the derivation of the following recommendations for e-skills development in FLE: 1) to critical review of the curriculum content to accommodate the dynamics of digital society input; 2) to review and update the FLE curriculum content interconnectivity and learning outcomes to accommodate the interoperable interface of skills, customized to facilitate professional activity and language application in the intensely digitized world; 3) to devise a flexible model of FLE content upgrade to meet the dynamic transdisciplinary requirements of the job market in the digital economy of the post-pandemic timespan and to enhance the universality of professional application for foreign languages majors in the digital age.

The presented study is limited in scope to the indicative survey results, exemplifying the interoperable dimensions of e-skills development and assessment for Oriental and European languages programs in the capital city university of Ukraine, induced by Covid-19 measures. The study results have the potential to be furthered and elaborated in the assessment of interdisciplinary and interoperable digital skills adaptability for separate groups of FLE stakeholders, according to roles and tasks performed in the language acquisition workflow, as well as according to age and entry digital literacy level. The perspective of the study is in scaling the inquiry to estimate the parameters of digital literacy formation for separate groups of source and target languages acquired, for different types of e-learning tools used for foreign languages acquisition, as well as to diagnose interdisciplinary digitization trends of FLE across countries of Asia and countries of Europe.

\section{ACKNOWLEDGEMENT}

Empirical findings and survey procedures have been conducted under the auspices of the Integrated Research framework of Romance Languages and Typology Chair of Borys Grinchenko Kyiv University European Languages And Literatures Development In Cross-Communication Context (0116U006607) and Integrated Research framework of Oriental Languages and Translation Chair of Borys Grinchenko Kyiv University Oriental Studies Development in the framework of Higher Education Internationalization (0116U007073). 
DIGITAL SKILLS DEVELOPMENT FOR FOREIGN LANGUAGES EDUCATION IN UKRAINE

\section{REFERENCES}

Abbott, S. 2013. The Glossary of Education Reform. Retrieved from Edglossary: http://edglossary.org/hidden-curriculum

Al-Jardani, Khalid Salim. 2020. E-Learning in Higher Education: Challenges and Opportunities. International Journal of Innovation, Creativity and Change, 14 (11), pp. 58-64.

Almalki, S. 2016. Integrating Quantitative and Qualitative Data in Mixed Methods Research - Challenges and Benefits. Journal of Education and Learning, 5(3), pp. 288-296.

American Library Association. 2020. Digital Literacy. Retrieved from: https://literacy.ala.org/digitalliteracy.

Callaos, N., \& Marlowe, T. 2020. Inter-Disciplinary Communication Rigor. Rigor and Inter-Disciplinary Communication: Intellectual Perspectives from Different Disciplinary and Inter-Disciplinary Fields. TIDC, LLC. pp. 4-29.

Davies, A., \& Fidler, D. 2011. Future Work Skills 2020. Retrieved from Institute for the Future for University of Phoenix Research Institute: https://www.iftf.org/uploads/media/SR 1382A_UPRI_future_work_skills_sm.pdf

Dillman, D. A., Smyth, J. D., Christian, Leah Melani, 2014. Internet, Phone, Mail and Mixed-Mode Surveys: The Tailored Design Method, 4th edition. John Wiley: Hoboken, NJ.

DosReis, A. 2015. To Be a (Blended) Teacher in the 21st Century - Some Reflections. International Journal of Research in E-learning, 1(1), pp. 11-24.

DQ Global Standards. 2019. World's first global standard for digital literacy, skills and readiness launched by the Coalition for Digital Intelligence. Retrieved from DQ Global Standards Report: https://www.dqinstitute.org

Eduventures. 2020. TechLandscape. Retrieved from:https://encoura.org/2020-eduventures-techlandscape-heres-what-to-expect/.

European Commission. 2020. Digital Competence 2020. Retrieved from European Commission: https://ec.europa.eu/jrc/en/digcomp/digital-competence-framework

European Commission. (2020). European E-Competence Framework Guideline. Retrieved from European Commission: https://www.ecompetences.eu/

Frodeman, R. (Ed.). 2017. The Oxford Handbook of Interdisciplinarity (2 ed.). Oxford: Oxford University Press.

Gródek-Szostak, Z. , Suder, M., Piechaczek, A., Siguencia, L.O. 2021. Assessment and Comparison of Digital Competences in Education for Selected European Countries. European Research Studies Journal, 24(1), pp. 348-361.

Heim M. 1993. The Metaphysics of Virtual Reality. LA: Westport Publishers.

Holbrook, J. B. (2013). What is interdisciplinary communication. Reflections on the very idea of disciplinary integration. Synthese, 190(11), 1865-1879.

Hymes, D. H. 1972. Communicative competence. In Sociolinguistics: selected readings. Harmondsworth : Penguin, pp. 269-293.

Interoperability Working Group. 2021. Definition of Interoperability. Retrieved from Interoperability Working Group: http://interoperability-definition.info/en/

Jacobs, J., \& Frickel, S. 2009. Interdisciplinarity: a critical assessment. Annual Review of Sociology, 35, pp. 43-65.

Liesa-Orús M., Latorre-Cosculluela C., Vázquez-Toledo S. and Sierra-Sánchez V. 2020. The Technological Challenge Facing Higher Education Professors: Perceptions of ICT Tools for Developing 21st Century Skills. Sustainability, 12 (5339), pp. 2-14. 
IADIS International Journal on WWW/Internet

Makhachashvili, R., \& Semenist, I. 2021. Covid-19 Context For Meta Assessment Of Digital Learning On European And Oriental Languages Programs. Proceedings of the 12th International Multi-Conference on Complexity, Informatics and Cybernetics, 2, pp. 129-134.

Makhachashvili, R., \& Semenist, I. 2021. Interdisciplinary Skills Development Through Final Qualification Assessment: Survey Study for European and Oriental Languages Programs. Proceedings of the 12th International Multi-Conference on Complexity, Informatics and Cybernetics, pp. 144-152.

Slater, T. 2013. Cross-Domain Interoperability. Retrieved from Network Centric Operations Industry Consortium - NCOIC: https:// www.ncoic.org

Shannon, C. E. 1948. A Mathematical Theory of Communication. Bell System Technical Journal, 27 (3), pp. 379-423.

Supriyatno T., Kurniawan F. 2020. A New Pedagogy and Online Learning System on Pandemic COVID 19 Era at Islamic Higher Education. 6th International Conference on Education and Technology (ICET), pp. 7-10.

Troussas C., Krouska A. and Sgouropoulou C. 2021. A Novel Teaching Strategy Through Adaptive Learning Activities for Computer Programming. Transactions on Education, 64 (2), pp. 103-109.

UNESCO. 2018. ICT Competency Framework for Teachers. Retrieved from UNESCO https://unesdoc.unesco.org/ark:/48223/pf0000265721

Vernadsky V. 1991. Scientific thought as a planetary phenomenon. M.: Academia

Wulf, G., \& Shea, G. 2002. Principles derived from the study of simple skills do not generalize to complex skill learning. Psychonomic Bulletin \& Review, 9, pp. 185-211.

World Economic Forum. 2020. The Future of Jobs Report. Retrieved from World Economic Forum: http://www3.weforum.org/docs/WEF_Future_of_Jobs_2020.pdf

World's first global standard for digital literacy, skills and readiness launched by the Coalition for Digital Intelligence. 2019. The DQ Global Standards Report. Retrieved from: https://www.dqinstitute.org/ 